\title{
To Apply or not to apply for a Job Efficiently: That is the Question
}

\author{
M. Iglesias \\ School of Tourism, Hospitality and Gastronomy CETT-UB, University of Barcelona
}

\begin{abstract}
This paper presents a pedagogical proposal for higher education students of English as a Foreign Language (EFL) who need to be trained on how to apply for jobs. Students are required to produce oral elevator pitches, written CVs with covering emails, and take part in job interview simulations. The students' oral productions are video recorded, and self, peer and teacher feedback is provided through a class blog. The paper includes an account of the rationale and lessons plan, as well as the materials used and authentic examples illustrating their implementation. This approach was followed during the academic year 2018-19 with a group of first year students of the Bachelor's degree in Tourism in the context of the School of Tourism, Hospitality and Gastronomy CETT-UB, from the University of Barcelona (Spain). The students' level of English was B2 according to the Common European Framework of Reference for Languages. Due to their very limited or even non-existent work experience, the development of their communicative competence in EFL with a specific professional orientation is a must so as to become successful job applicants for middle or top management positions in the tourism sector. The most significant aspects of the teaching-learning-assessment process are reported, along with the main drawbacks, limitations, practical implications and future research avenues.
\end{abstract}

\section{Introduction}

In the era of the Internet of things, social media, youtubers and virtual reality, education can no longer follow a traditional approach. Times have changed, the world has changed and learners have changed, so teaching and teachers have also had to face change in terms of why, what, how, where and even when to teach. In Europe, this transformation has been particularly noticeable in primary and secondary education. However, higher education seems to be less proactively willing to embrace change and is rather anchored in pre-constructivist conceptions and methodologies. A constructivist approach entails that "each individual constructs his or her own reality and therefore learns different things in very different ways even when provided with what seem to be very similar learning experiences" (Williams \& Burden, 1997, p. 2).

The development of learners' competences is nowadays supposed to focus on facilitating applicability in real life professional contexts (Peguero et al., 2014). Communicative competence in a foreign language is one of those must-have skills, not only for future professionals in most sectors, but also for lifelong learning. More specifically, the acquisition of English as a Foreign Language (EFL) is fundamental for tourism students.

The need for a cross-curricular perspective to allow for knowledge transfer, coupled with the understanding that teaching-learning-assessment processes should be integrated to enable significant language acquisition in higher education environments, underlie the pedagogical proposal described in this paper. Such proposal was designed and implemented in the academic 
year 2018-19. The participants were a group of 12 first year students of the Bachelor's degree in Tourism at the School of Tourism, Hospitality and Gastronomy CETT-UB, from the University of Barcelona, in Spain.

The underpinning constructivist principles follow along the same lines as reported past course of action in this educational setting (Iglesias, 2013a, 2013b). They involve the fostering of formative continuous assessment, which in turn requires informing students systematically of assessment criteria and procedures. They must play an active role in their own learning and reflect on their competence development in professionally-oriented situations. The spotlight is on learners' communication strategies and on their pragmatic and socio-cultural competences. Language accuracy is taken care of, as well as the adequacy and coherence of their performance in accordance with a formal register. Therefore, accuracy and adequacy problems are positively regarded as opportunities for feedback and progress (Iglesias, 2013b).

Since the key to efficient communication lies in finding the balance between accuracy and pragmatic fluency, pronunciation is also worked on at a supra segmental level to minimise communication breakdowns caused by mispronunciation interference. Mistakes are dealt with constructively, and self-correction and peer-correction are carried out under the teacher's supervision to promote students' awareness of their strong and weak points by reflecting upon them (Iglesias, 2013a).

\section{Pedagogical Design}

At the end of the academic year 2017-18 the Career Services Department from the School of Tourism, Hospitality and Gastronomy CETT-UB held an orientation session for CETT-UB language teachers. As the name indicates, Career Services is in charge of managing CETT-UB students' internships and job offers coming from the tourism, hospitality and catering industry worldwide. Career Services also organises workshops for CETT-UB students providing them with practical assistance and guidance on how to take part in candidate selection processes.

Following the guidelines provided by Career Services, a lesson unit was designed aimed at first year CETT-UB students of the Bachelor's degree in Tourism in the context of their EFL class. These students had taken a placement test before starting their classes according to which their level of EFL was B2.2 within the Common European Framework of Reference for Languages. Their communicative competence in EFL was, therefore, upper intermediate. However, as most of them were 18 years old and their professional experience was rather scarce (if not totally nonexistent), they lacked the job search skills and professional lexicon required to apply for a job. Their EFL course consisted of 120 teaching hours, beginning in September and ending in May, and as these students had been allocated to an advanced level group, their syllabus had a business English approach combined with the requirement to conduct an academic research project. Yet, applying for a job was not initially part of their syllabus, since this area is usually covered by second year students whose level of EFL is rather B2.1. The textbook used by advanced level students does not deal with this topic, either. Hence the need to design special learning materials adapted to these students' profile, to keep to the orientations provided by Career Services in order to avoid any cross-curricular contradictions, and to guarantee that what they learn can be transferred to future real life situations in practical terms.

The vehicle used as a platform to facilitate the teaching-learning-assessment process is a class blog: Welcome to CETT's blog (http://englishcett.blogspot.com). The blog was created in 2007 and is often used as a tool for feedback provision and peer assessment (Iglesias, 2014). In previous academic years, the students' oral skills have been developed by video recording their oral productions, posting them on the blog with the students' prior consent, and asking them to comment on their own performance and their classmates' performances. Their comments are often 
complemented by teacher feedback and follow a set of guidelines based on assessment criteria they are familiar with. As a matter of fact, since the beginning of the academic period students usually receive training on how to interpret each criterion, how to talk about their strengths and weaknesses, and how to contribute to their learning process constructively by focusing on positive points and aspects that need reinforcement and improvement.

Other skills are also worked on through the class blog, such as writing skills and academic research skills, usually linked to the promotion of critical thinking. The blog allows for the provision of instruction while encouraging interaction and reflection as well, producing a mirror effect. Thus, the class blog can be considered the best medium to support a job search learning unit, which has been designed and structured in different stages.

\subsection{Stage 1: Introduction}

The first stage comprises a warming-up activity to contextualise the topic and to elicit students' prior knowledge and experience in relation to jobs and careers. Several open questions are posed by the teacher to generate a discussion.

Initial advice is offered by the teacher through Welcome to CETT's blog by means of a post entitled "Applying for a job" (see Annex 1). It includes a number of tips and useful links aimed at helping students to video record an elevator pitch, to produce a written or a video CV and a covering email, and to prepare and practice for a job interview by employing some online resources such as Canva (https://www.canva.com) or Hirevue (https://www.hirevue.com), along with practical hints and examples.

\subsection{Stage 2: Elevator pitch}

Having dealt with the theory, the post "Create your elevator pitch" on Welcome to CETT's blog prompts students to start with the practice by creating and delivering their own elevator pitches individually, video recording and posting them, and commenting on their performances following the usual set of assessment criteria (see Annex 2).

Such criteria are concerned with linguistic use, i.e. grammar and vocabulary accuracy, range and register adequacy; task achievement, i.e. the efficient achievement of communicative purpose, content relevance and extent; fluency and pronunciation, i.e. speech flow, intonation, stress and rhythm; and communicative resources, i.e. the use of linguistic and non-linguistic resources, support materials and attitude. As mentioned above, students should already understand the meaning of this meta language, since they have used it previously to comment on their utterances. Moreover, they have already got used to the idea of analysing their own speeches and helping each other thanks to their comments.

\subsection{Stage 3: CV and covering email}

The next stage consists in writing a CV and a covering email in pairs, as instructed on Welcome to CETT's blog though the post "Job interview simulations" (see Annex 3). Students are offered a set of authentic job ads found on the Internet and slightly edited by the teacher. Each pair reads the job ads carefully, weighing up the pros and cons of applying for each post so as to choose one. Their choices are then put in common and a consensus needs to be reached, as all the students must apply for the same job.

After selecting the job advertisement, each pair of students must invent a suitable candidate profile and use Canva to design their CV as a single applicant. Due to their limited real professional backgrounds, students can look for inspiration on the Internet and use their imagination. Once they 
have completed their $\mathrm{CV}$, they must write a covering email and send their $\mathrm{CV}$ as an attachment to the contact person - the teacher, in this case.

The teacher revises the CVs and emails and returns them to the students so that they can rewrite an improved version and/or write their own CVs using their real data following the model they have used as imaginary applicants. This can be a very useful basic resource that can be customised when applying for an internship or a job vacancy in the future.

\subsection{Stage 4: International internships presentation}

The following session is conducted by Career Services. It consists of a general presentation in English on international internships at hand for CETT-UB students. The presentation supplements all the aspects that have been worked in the EFL class, and includes information on internship opportunities abroad, as well as the testimonials and advice supplied by CETT-UB current students and alumni, both face to face and through Skype.

\subsection{Stage 5: Job interview}

The last stage of the teaching-learning-assessment process focuses on how to face a job interview by means of two more sessions. In the first one, after listening to a recording of a personnel manager explaining how he usually interviews and selects candidates (taken from New Insights into Business Unit 2), students suggest possible questions that they might have to answer at a job interview. Additionally, they read other similar questions listed on the post "Job interview simulations", and discuss their potential replies.

Students are now ready to take part in simulated job interviews and take turns to be interviewers and interviewees. Each student must ask a couple of questions as an interviewer, and everybody has to apply for the same job using the materials they have prepared in previous sessions. Their interviews are video recorded by the teacher. Afterwards they must write their comments on their own and their classmates' performances following the usual guidelines, and the teacher collects their reflections to upload them on Welcome to CETT's blog, along with anonymous teacher remarks. Students must finally vote anonymously for the best candidate, who obtains a prize.

In the last session, the group watches the video recordings and goes through the feedback on strengths and weaknesses posted on the blog. This is complemented with open oral improvement suggestions and a group discussion, and the process concludes with an evaluation of the learning unit by means of a "Mid-term self-assessment sheet" (see Annex 4).

\section{Implementation}

The pedagogical design was put into practice throughout seven two-hour sessions. The procedures followed in each session will be described in detail and the materials used will be supplied. The lesson plan report for each session has been adapted from Your Teacher Training Handbook (McGrath \& Coles, 2014).

\subsection{Session 1}

The first session took place on 22 November 2018.

- Learning objectives: By the end of this session students should have a clear idea of the procedures involved in applying for a job. They should also understand how to create an elevator pitch. 
- Learning-teaching activities and grouping: We start with an oral class discussion about students' work experience, participation in employee selection processes and professional expectations. We go together through the blog posts of 12 November 2018 to make sure that students understand the different stages involved in applying for a job, the recommendations given and the examples. Students need to video record their own elevator pitches individually at home and upload them on the blog before the following session.

- Setting and resources: Usual classroom and projector. Welcome to CETT's blog posts 12 November 2018 "Applying for a job" and "Create your elevator pitch".

- Assessment of learning outcomes: Throughout the following sessions.

- Problems and solutions: Even though the blog is full of videos recorded by CETT-UB students in the past with their consent, this year some students are reluctant to upload their videos on the blog. They do not feel embarrassed to show their performance to their classmates, but they prefer not to show them to the rest of the school. Instead, they agree to email their videos to their teacher so that they can be used in the next session.

- Evaluation of session success: For most students this has been their first realistic taste of job application in EFL, so the introductory target has been achieved. In spite of their lack of selfconfidence students seem motivated.

\subsection{Session 2}

The second session took place on 27 November 2018.

- Learning objectives: By the end of this session students should be able to identify strengths and weaknesses in their elevator pitches.

- Learning-teaching activities and grouping: The session starts with an oral class discussion about the main difficulties they have encountered when producing their elevator pitches. We watch each video all together, and after each performance they have some minutes to take notes in order to post their comments on the blog anonymously. Each student must write some positive aspects and some improvement suggestions for each elevator pitch.

- Setting and resources: Computer room and projector. Videos of elevator pitches stored in private Youtube channel (https://studio.youtube.com/channel/UC8hSWFHdkkrliA2ZPU5pjxw). Welcome to CETT's blog post 12 November 2018 "Create your elevator pitch".

- Assessment of learning outcomes: Anonymous peer and teacher analytic assessment is provided in writing through the blog. Self, peer and teacher holistic feedback is also provided orally. Taking into account that most of the students are 18 years old and that they were unfamiliar with elevator pitches, most of them have done a good job, but there is also room for improvement. After showing some of the videos to the head of Career Services, she agrees that this has been a very good first step, and that more orientation and work are needed from this starting point in the future, ideally by means of cross-curricular cooperation between the school's Career Services and English teachers.

- Problems and solutions: As it is not possible to watch all the elevator pitches in this session, some of them are left for a forthcoming session.

- Evaluation of session success: Although not all the videos have been examined, students seem to have grasped the concept and purpose of this task successfully. Their motivation and implication have been considerable.

\subsection{Session 3}

The third session took place on 29 November 2018.

- Learning objectives: By the end of this session students should be able to write a CV and a covering email. 
- Learning-teaching activities and grouping: We go together through the blog post of 12 November 2018 to revise the guidelines for writing CVs and covering emails. In pairs, students are given the printouts of four authentic advertisements published on the Internet and edited by the teacher for the sake of confidentiality. The ads aim to recruit an Assistant Front Office Manager, a Corporate Travel Consultant, a Hotel Sales Co-ordinator, and a Meetings \& Events Manager, all of them based in the UK. Students must read the job description, requirements and recruitment conditions, weigh up the pros and cons for each post, and choose the one each pair would like to apply for. After a class discussion to put their choices in common, they must all agree on the job ad which everybody will focus on. In this case, almost everybody seems attracted to the post of Meetings \& Events Manager (see Annex 5). Each pair has to create an imaginary user profile, open a Canva account, and use it to write a CV. They can look for information on the Internet to invent a candidate profile based on the job advert, and draw on the wide range of templates and examples available at Canva. When they finish, the teacher supervises each pair's CV. Finally, each pair needs to write an email, attach their CV, and send it to their teacher as the contact person.

- Setting and resources: Computer room and projector. Welcome to CETT's blog post 12 November 2018 "Applying for a job". Photocopies of four job ads. Canva website.

- Assessment of learning outcomes: Although some teacher feedback is provided in class, most of the revision will take place in a forthcoming session, when the teacher will return each student pair their corrected CVs and emails, along with verbal comments and improvement suggestions.

- Problems and solutions: Some student pairs need more time to do this task, so the teacher cannot supervise all of them in the classroom. They are required to finish the task by themselves and send it before the next session.

- Evaluation of session success: Given the task complexity and varied pace of work, the fact that all the students have understood the task, have managed to carry it out, and have been able to complete it or will be completing it on their own is very satisfactory.

\subsection{Session 4}

The fourth session took place on 4 December 2018.

- Learning objectives: By the end of this session all the students should receive feedback so as to enhance their elevator pitches, CVs and covering emails.

- Learning-teaching activities and grouping: All the class watches the video recorded elevator pitches left from session 2. After each performance, students take notes in order to post anonymously their positive comments and improvement suggestions on the blog. General observations are also made orally by students about their own and their classmates' productions. As the teacher has printed out and revised the CVs and covering emails she has received from each pair of students, she gives them the corrections, with comments and improvement suggestions. Some time is devoted to make sure that teacher feedback is understood and doubts are clarified at each pair of students' demand. Students are encouraged to rewrite them and elaborate their own authentic CVs.

- Setting and resources: Computer room and projector. Videos of elevator pitches stored in private Youtube channel (https://studio.youtube.com/channel/UC8hSWFHdkkriiA2ZPU5pjxw). Welcome to CETT's blog post 12 November 2018 "Create your elevator pitch". Print outs of revised CVs and covering emails sent by students.

- Assessment of learning outcomes: Written anonymous peer and teacher analytic feedback on elevator pitches is posted on the blog. Self, peer and teacher holistic feedback is also supplied orally. Written detailed corrections of CVs and emails are provided by the teacher to each pair of students and strengthened orally. 
- Problems and solutions: A reduced number of students have not recorded their elevator pitches because they felt not self-confident enough or simply because they forgot. In addition, a couple of students missed session 3 and did not write their CVs and covering emails. These students are able to participate in session 4 by commenting on their classmates' productions and taking them as an example. All of them are invited all the same to produce these tasks on their own and send them to their teacher for feedback. On the other hand, as we are heading towards the end of the semester, students are busy with other projects and they do not have time to elaborate their own $\mathrm{CVs}$, which can be submitted next semester for teacher revision. For now, students just need their invented profiles and CVs to take part in future simulated job interviews. Next day is a bank holiday, and afterwards, session 5 will be entirely conducted by Career Services. This means that job interview simulations will be postponed for session 6 .

- Evaluation of session success: Despite the obvious flaws in students' productions, the fact that inexperienced students have been able to elaborate an elevator pitch, a CV and a covering email is to be regarded as a success in itself. The students' commitment is also very positive.

\subsection{Session 5}

The fifth session took place on 11 December 2018.

- Learning objectives: By the end of this session students should acquire knowledge on a wide range of aspects related to professional mobility programmes abroad.

- Learning-teaching activities and grouping: Career Services staff gives a short talk on what international internships entail for students, what companies demand nowadays, and which destinations and positions are the most demanded by trainees. After listening to two current CETT-UB students ' account of the professional mobility programmes that they have participated in, we also have the opportunity to interact with a CETT-UB alumni who at present has a top management position in Miami (US) thanks to his international mobility experience. Furthermore, some practical tips are provided with regard to intermediary companies, useful resources, grants, and internship vacancies. Finally, some recommendations are offered to help students to plan and prepare for their future internships overseas.

- Setting and resources: Lecture room and projector. Power point presentation elaborated by Career Services. Skype.

- Assessment of learning outcomes: No tangible outcomes derive from this session. However, some of the questions and concerns expressed by the students suggest that they have understood international mobility procedures and that their interest has been raised.

- Problems and solutions: The audience is composed of first year students mingled with students in their final years of the Bachelor's degree. The former cannot apply for an internship abroad yet, as these programmes are especially aimed at the latter. Nevertheless, this session is food for thought for first year students, who can thus start making plans for the future.

- Evaluation of session success: This session fits perfectly in the whole learning unit and has also enabled students to see the need to develop their job search skills for real practical purposes. Students generally seemed very interested and engaged most of the time.

\subsection{Session 6}

The sixth session took place on 13 December 2018.

- Learning objectives: By the end of this session students should be ready to take part in a job interview.

- Learning-teaching activities and grouping: To warm up, students do a listening comprehension exercise so as to find out the job interview procedures followed by a personnel manager in charge of an employee selection process. He also offers some practical advice on how to prepare 
for an interview. This leads the class to brainstorm orally possible questions that candidates may be asked. We all go through a set of such questions posted on the blog and have a class discussion about how to reply to them, with some individual students contributing with their personal answers. Next, students are told that they will participate in a job interview simulation, with a prize for the best candidate. They are required to read the job ad they chose in session 3 , as well as their imaginary CVs. Bearing in mind their imaginary profile, they need to think about the answers each one of them would give as a candidate being interviewed for the post of Meetings \& Events Manager. Tables and chairs are rearranged for an interview situation and students take turns to be interviewers and interviewees. Given the reduced number of students attending this particular session, each candidate must reply to at least two questions posed by each one of their classmates. All the interviewers sit down and can look at the photocopies during the process. Each candidate simulates they enter the room, greets the interviewers, sits down on the other side of the table, responds to questions and comments on them, says farewell and leaves the room. They may improvise as much as they wish, but must remember that they must keep to a formal register. The teacher is on one side of the room and video records every interview without any interruption. Once all the students have been interviewed, they must write on a sheet of paper their comments about each performance (including their own) following the usual procedure. This time the teacher collects all the anonymous observations to upload them on the blog, and feedback will be provided in the next session, when students will also be able to watch the video recorded interviews. Last but not least, students are required to write on a piece of paper the name of the best candidate, who receives a prize.

- Setting and resources: Usual classroom and projector. Recording taken from Listening Unit 2 of New Insights into Business (Tullis \& Trappe, 2000). Welcome to CETT's blog post 13 December 2018 "Job interview simulations". Photocopies of the Meetings \& Events Manager advertisement. Photocopies of interview questions. Cell phone or similar with video recording capacity. A prize -a notebook and pen set, in this case.

- Assessment of learning outcomes: Peer assessment is at the core of this simulation, and self assessment also intervenes as students are forced to challenge themselves and reflect on their own performances. Therefore, the focus is away from the teacher and constantly on the learner, who plays an active role and is significantly empowered to take control of the process. Teaching, learning and formative assessment are truly intertwined.

- Problems and solutions: This can be a very challenging task, particularly for more introverted students, who might not feel at ease neither as an interviewee nor as an interviewer. The class atmosphere needs to be very relaxed and friendly, and the teacher needs to carefully avoid any threatening, disrespectful or embarrassing situations. Students must understand that despite its usefulness and relevance for the future, this simulation is to be faced as a role play where all the students are actors on the same conditions. Announcing that there is a prize for the best candidate has a gamification component and can add extra motivation. However, it can also be a thorny issue in competitive groups with aggressive members, in which case a prize would not be advisable. In large groups several interviews can take place at the same time, as long as the classroom setting allows it and they do not interfere in each other's dynamics.

- Evaluation of session success: Class attendance has been quite reduced, so unfortunately not all the students have benefitted from this session. Those who have taken part in the simulation have showed a great deal of respect, involvement and willingness to do their best. As a result, this has been a very fruitful session for them.

\subsection{Session 7}

The seventh session took place on 18 December 2018. 
- Learning objectives: By the end of this session students should be able to identify strengths and weaknesses in their job interview interactions.

- Learning-teaching activities and grouping: We watch each video all together and read the comments posted on the blog. After each performance, we talk about the positive aspects and make recommendations to overcome the defects and limitations. This is followed by an oral class discussion about the main difficulties they encountered when playing the roles of interviewees and interviewers. To conclude, we make a recap of the competences developed in the last sessions and students are given an evaluation sheet which they must complete individually in writing with regard to this learning unit.

- Setting and resources: Usual classroom and projector. Welcome to CETT's blog post 13 December 2018 "Job interview simulations". Videos of job interview simulations stored in private Youtube channel (https://studio.youtube.com/channel/UC8hSWFHdkkrIiA2ZPU5pjxw). Photocopies of "Mid-term self-assessment sheet".

- Assessment of learning outcomes: Written anonymous self, peer and teacher analytic feedback on job interview simulations is posted on the blog. Self, peer and teacher holistic feedback is also supplied orally. Written feedback on the job application learning unit is provided by students to the teacher individually.

- Problems and solutions: Some students who did not come to session 6 and did not carry out the job interview simulations attend session 7. Nevertheless, they comment on the videos and contribute with their observations. On the other hand, some students who attended session 6 miss session 7 . They can still watch their own videos by themselves through a link sent by the teacher and read the related comments on the blog.

- Evaluation of session success: With this session the learning unit has gone full circle. Hands-on knowledge has been positively acquired and competences have been developed, as stated by most of the students who have undertaken the job application tasks. The students' evaluation of different aspects of the teaching-learning-assessment process has differed slightly depending on factors like personal motivation, personality and preferences, task participation and involvement, and communicative weak points. Nonetheless, the learning objectives seem to have been achieved, by and large.

\section{Conclusion}

As it has been reported, the pedagogical proposal described in this paper was successfully implemented, and solutions were found to counterbalance every drawback. On the whole, the learning objectives were met, and the evaluation provided by the students was also positive.

Admittedly, the scope of this pilot action was limited and there is obviously room for improvement, for example with respect to student participation in simulated job interviews. Future lines of action could aim at implementing this learning unit in other groups of students with similar profiles to expand its reach. In this new scenario the challenge would be how to manage its implementation in numerous groups and how to handle the associated workload sustainably.

Another option worth considering may be extrapolating some aspects of this pedagogical proposal to the acquisition of other languages or to other areas, such as human resources. As a possible follow-up in this respect, the collaboration initiated with Career Services could be strengthened and intensified in order to overcome the pragmatic weaknesses in student productions.

This learning unit can also be adapted to other educational programmes or institutions, so its applicability potential could be explored. Moreover, further research can analyse student outcomes and study how to refine the procedures to optimise processes and results.

All in all, the practical implications of adopting a learner-centered approach like the one that has been presented in this paper constitute a leap forward for learners and a step aside for teachers, who 


\section{International Conference on Research in Education}

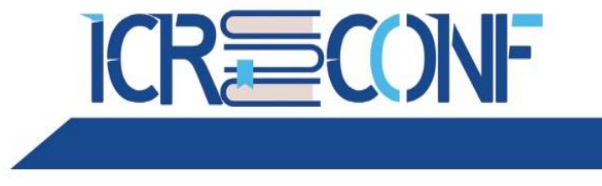

5-7 APRIL, 2019

BARCELONA, SPAIN

thus play the role of facilitators of competence development through teaching-learning-assessment in higher education environments.

\section{References}

1. Berger, L.: How To Create Your 30 Second Elevator Pitch!, 2017. Retrieved from https://www.youtube.com/watch?v=Lb0Yz_5ZYzI.

2. Doyle, A.: Elevator Pitch Examples and Writing Tips, The Balance Careers, 2018a. Retrieved from https://www.thebalancecareers.com/elevator-speech-examples-and-writing-tips-206197.

3. Doyle, A.: Tips for Creating a Video Resume, The Balance Careers, 2018b. Retrieved from https://www.thebalancecareers.com/tips-for-creating-a-video-resume-2064219.

4. Iglesias, M.: "An Analysis of the Communication Strategies Employed by Learners of English as a Foreign Language", Linguistics and Literature Studies, 1(2), 88-104, 2013a. Retrieved from http://www.hrpub.org/journals/article info.php?aid=329.

5. Iglesias, M.: "Practical Implications of a Constructivist Approach to EFL Teaching in a Higher Education Context", Journal of University Teaching \& Learning Practice, 10(2), 2013b. Retrieved from https://ro.uow.edu.au/jutlp/vol10/iss2/3.

6. Iglesias, M.: "Digital Technologies and Foreign Language Learning in Tourism Studies", eLearn Center Research Paper Series, 8, 2014. Retrieved from http://elcrps.uoc.edu/elcrps/index.php/elcrps/article/view/2290.html.

7. McGrath, J., \& Coles, A.: Your Teacher Training Handbook, Routledge, 2014.

8. Peguero, D., Sanmartín, G., \& Iglesias, M.: "Needs Analysis for the Curricular Design of Tourism Studies in the Dominican Republic: Focusing on Key Competences and Rethinking Professional Profiles to Enable the Tourism Sector's Prospective Development", Ara Journal of Tourism Research, 4(1), 71-82, 2014. Retrieved from http://revistes.ub.edu/index.php/ara/article/view/19041.

9. Personal Career Management: How to write the perfect email covering letter, The Guardian, 2017. Retrieved from https://jobs.theguardian.com/article/how-to-write-the-perfect-email-covering-letter/.

10. Tullis, G., \& Trappe, T.: New Insights into Business, Pearson Education, 2000.

11. UK Gatton College: Elevator Pitch-Good Example, 2014. Retrieved from https://www.youtube.com/watch?v=JH0Thez9gvA.

12. Williams, M., \& Burden, R. L.: Psychology for Language Teachers: A Social Constructivist Approach, Cambridge University Press, 1997.

\section{Annex 1}

\section{Applying for a job}

Read the following tips for job application.

1. Each CV should be adapted to the personality and style of the candidate, and always in line with the sector/post to which it is addressed. It is recommended that it is only one page long and that you include an introductory paragraph (see examples and templates at https://www.canva.com/es_en/). Following a chronological order isn't a must and you can highlight the most relevant information in bold.

2. It is advisable for the CV to include a Skype user, link or icon of the professional social networks in which the candidate is. In this sense, both the content of the CV and the information included in these social networks (e.g. Linkedin, Hosco or Instagram) should be detailed, relevant and carefully elaborated. 


\section{International Conference on Research in Education}

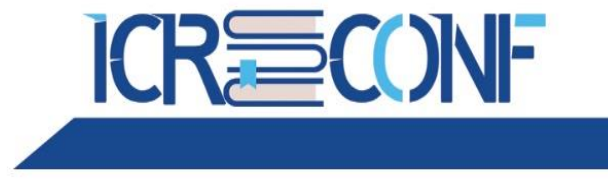

5-7 APRIL, 2019

BARCELONA, SPAIN

3. The covering e-mail with which you will contact the company or accompany your CV must be accurate (see tips at https://jobs.theguardian.com/article/how-to-write-the-perfect-email-coveringletter/). It's advisable to use a gmail address with your name and surname.

4. You must attach your CV in pdf, which you should also revise in depth, and provide clear contact details without being too personal (e.g. avoid your date of birth, address, age or marital status). In Spain it's customary to include a picture of yourself, but not when applying abroad. You can also produce a video CV (see tips at https://www.thebalancecareers.com/tips-for-creating-avideo-resume-2064219).

5. Moreover, you can practice for job interviews by means of recorded video interviews (available at https://www.hirevue.com/, for example). You can record yourself answering to questions.

6. Bearing the interview in mind, you can also work on your elevator pitch, which allows you to introduce yourself and summarise for up to 1.5 minutes some key aspects, such as who I am? what do I look for? and why am I applying? (see tips at https://www.thebalancecareers.com/elevatorspeech-examples-and-writing-tips-2061976).

7. Most formal interviews nowadays take place in a relaxed atmosphere. Some interviews include unexpected code switching into English to check oral skills. During the interview you shouldn't be vague and rather provide specific examples. Some questions you might have to reply to are what do you expect to find here? or why should we choose you instead of another candidate? You can also ask questions.

8. You should have a register of your applications. Be coherent and apply sensibly, for the right post/company. It's important to have searched for information about the company well in advance, and to be aware of the pros and cons.

Good luck with your job hunt!

\section{Annex 2}

\section{Create your elevator pitch}

Introducing yourself well sets the stage for a professional conversation, whether that's at a networking event, with a colleague or at the beginning of an interview. One tool many people use to make introductions simple and effective is the elevator pitch.

1. Use the following links to learn how to create and deliver your elevator pitch:

- Tips: https://www.thebalancecareers.com/elevator-speech-examples-and-writing-tips2061976

- Tips \& example: https://www.youtube.com/watch?v=Lb0Yz_5ZYzI

- Example: https://www.youtube.com/watch?v=JH0Thez9gvA

2. Record and post your own elevator pitch. 


\section{International Conference on Research in Education}

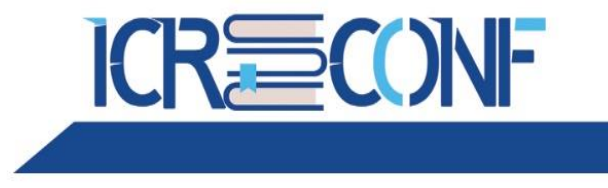

5-7 APRIL, 2019

BARCELONA, SPAIN

3. Watch your classmates' speeches and make constructive comments. Have the guidelines been followed? What are the main strengths of each elevator speech? Write at least one strength and one weakness for each elevator pitch. How could they be improved? Provide feedback in relation to the following assessment criteria:

- Linguistic use: grammar/vocabulary accuracy, range and adequacy.

- Task achievement: efficient achievement of communicative purpose, content relevance and extent.

- Fluency and pronunciation: speech flow, intonation, stress and rhythm.

- Communicative resources: use of linguistic and non-linguistic resources, support materials and attitude.

\section{Annex 3}

\section{Job interview simulations}

Get ready for a job interview step by step.

1. Choose a job ad in pairs, consider the pros and cons for each option and reach a consensus. All candidates must apply for the same job!

2. Create a candidate profile for that position and elaborate your CV at https://www.canva.com..

3. Write a covering email and attach your CV. Send it to the contact person.

4. Listen to some pieces of advice for successful job interviews.

5. Go through the following questions and think about your possible answers. What other questions could you be asked at a job interview?

- Tell me about yourself.

- What do you think are your strengths and weaknesses?

- We have a lot of applicants for this job, why should we appoint you?

- Which is more important to you: status or money?

- How long do you think you'd stay with us if you were appointed?

- Why do you want to leave your present job?

- What would you like to be doing ten years from now?

- What are you most proud of having done recently?

- What is your worst fault and what is your best quality?

- Don't you think you're a little young/old for this job?

- What are your long-range goals?

- What excites you about the job you're doing now?

- How would you rate your present boss?

6. Take turns to be interviewers and interviewees. All of you must apply individually for the job you selected using the profile you created. Vote for the best candidate... there's a prize for him/her! 


\section{International Conference on Research in Education}

7. Comment on your job interviews. Have the guidelines been followed? What are the main strengths of each candidate? How could they improve their performance? Were their answers to the questions suitable? Do you think they would get the post? Why/why not? And what about the interviewers' questions... were they pertinent? Did the interviewers do a good job? Provide the interviewees/interviewers with feedback relating to the following assessment criteria:

- Linguistic use: grammar/vocabulary accuracy, range and adequacy.

- Task achievement: efficient achievement of communicative purpose, content relevance and extent.

- Fluency and pronunciation: speech flow, intonation, stress and rhythm.

- Communicative resources: use of linguistic and non-linguistic resources, support materials and attitude.

\section{Annex 4}

\section{Mid-term self-assessment sheet}

Tick the appropriate box. At the moment I can:

\begin{tabular}{|l|l|l|l|}
\hline Analyse and argue & + & $+/-$ & - \\
\hline Give a formal presentation & & & \\
\hline Pay attention to fluency and pronunciation & & & \\
\hline Pay attention to language accuracy and range & & & \\
\hline Pay attention to language register and socio-cultural conventions & & & \\
\hline Produce a video recorded elevator pitch & & & \\
\hline Take part in a job interview orally as an applicant & & & \\
\hline Take part in my classmates' assessment reflectively & & & \\
\hline Take part in my own assessment reflectively & & & \\
\hline Use communicative strategies & & & \\
\hline Write a covering email & & & \\
\hline Write a CV & & & \\
\hline
\end{tabular}

Tick the appropriate box. Now I think:

\begin{tabular}{|l|l|l|l|}
\cline { 2 - 4 } \multicolumn{1}{l|}{ I am more aware of my strengths and weaknesses } & + & $+/-$ & - \\
\hline I am more self-confident as a language user & & & \\
\hline I am a more communicative speaker & & & \\
\hline I have profited from the classes & & & \\
\hline I have profited from my classmates' feedback & & & \\
\hline I have profited from my teacher's feedback & & & \\
\hline
\end{tabular}




\section{International Conference on Research in Education}

ICRㅡㅡ른

5-7 APRIL , 2019

BARCELONA, SPAIN

Please answer the following questions and justify them:

-Which of the above-mentioned aspects have been the most helpful/interesting/motivating so far?

-Which aspects have been the least helpful/interesting/motivating so far?

-Do you consider job search skills have been satisfactorily worked on?

-How do you think your English class can help you become successful job applicants?

-Do you think your progress as a learner of English has been significant?

\section{Annex 5}

\section{Placing people... first}

Search Consultancy is the UK's fastest growing "total recruitment solutions" company. With over three hundred consultants across fifteen specialist Divisions based throughout the UK our approach is unique. True client partnerships and our focus on "placing people first" are part of what makes us different. For the best advice on your career move, speak to Search. There's no-one better placed.

\section{Meetings \& Events Manager UK-NW-MANCHESTER}

This leading South Manchester Hotel is presently looking to recruit a high calibre Meetings \& Events Manager. Reporting to the Food \& Beverage Manager you will be responsible for running the Meetings \& Events Department consisting of 30+ rooms maximising guest satisfaction and hotel profitability. At least 2 years experience in a similar role within $4^{*}$ or $5^{*}$ properties is a must including forecasting, planning and budget control, staff recruitment and training. For further information on this challenging role call XXX. Salary $£ 20,000$. Reference: XXX.

\section{Additional Information}

Position Type: Full time, permanent

Ref. Code: XXX

\section{Contact Information}

Search Recruitment Consultancy Ltd. MANCHESTER 